\title{
El pasado a la luz del presente y del poder en las comedias históricas de José de Cañizares: algunas calas
}

\section{The Past in the Light of the Present and Power in José de Cañizares' History Plays: Some Samples}

\section{Renata Londero}

Universidad de Udine

ITALIA

renata.londero@uniud.it

[Hipogrifo, (issn: 2328-1308), 8.2, 2020, pp. 303-319]

Recibido: 25-05-2020 / Aceptado: 26-06-2020

DOI: http://dx.doi.org/10.13035/H.2020.08.02.19

Resumen. Bajo el lema ciceroniano historia magistra vitae, y en la estela de la comedia clásica, un dramaturgo cortesano y de entresiglos como José de Cañizares (1676-1750), en sus dramas históricos utiliza los eventos del pasado, mezclados con la ficción y la invención, con la finalidad de cuestionarlos mejor, y sobre todo de relacionarlos con la situación política de su tiempo, que con Felipe $V$ se abría al gobierno de la nueva dinastía de los Borbones. El corpus elegido incluye la comedia de privanza El picarillo en España, señor de la Gran Canaria (estrenada en el madrileño Teatro de la Cruz, en 1716), centrada en los conflictos entre Juan II, Álvaro de Luna y la nobleza de su atormentada época, y cuajada de sincronismos y anacronismos; y El pastelero de Madrigal, rey don Sebastián fingido, cuya intriga se coloca en la época del rey don Sebastián de Portugal, tras cuya muerte en la batalla de Alcazarquivir, en 1578, se desataron encarnizadas luchas dinásticas que finalizaron en 1581, cuando el país cayó bajo el dominio español: el texto se compuso en 1706, mientras se estaba combatiendo la Guerra de Sucesión, aún lejos de su solución militar y política. Otras comedias que se examinan son La Poncella de Orleans, colaborada con Antonio de Zamora y explícitamente francófila, que también se escribió en 1706, y se estrenó en Madrid en 1707, para celebrar el embarazo de la primera esposa de Felipe V, María Luisa de Saboya; y La banda de Castilla, y due- 
lo contra sí mismo, de la que se conserva un testimonio manuscrito del año 1727 en la BNE (Ms. 16.594). En este trabajo, se pretenden analizar las citadas piezas históricas de Cañizares, con la finalidad de estudiar su peculiar tratamiento del pasado con vistas al presente, y su mentalidad fronteriza, oscilante entre el Barroco y la llustración.

Palabras clave. Cañizares; entresiglos; teatro histórico; monarquía; pasado; presente; ficción; historia.

Abstract. Under the Ciceronian motto historia magistra vitae and in the wake of the Spanish comedia, a court dramatist who lived between two centuries, José de Cañizares (1676-1750), in his history plays makes use of past events mingled with fiction and invention in order to discuss them better and above all to link them to the political situation of his own time, which was starting with the government of a new dynasty (the Bourbons) during Philip V's reign. The corpus selected includes the "privanza" comedy El picarillo en España, señor de la Gran Canaria (played for the first time in Madrid's Teatro de la Cruz in 1716), focused on the conflicts between king John II of Castile, Álvaro de Luna and the aristocracy of their tormented age, and full of synchronisms and anachronisms; and El pastelero de Madrigal, rey don Sebastián fingido, whose plot is set during the time of king Sebastian of Portugal, after whose death in the battle of Alcazarquivir in 1578 harsh dynasty fights broke out, ending in 1581, when the country fell under Spanish domain: the play was written in 1706, while the War of the Spanish Succession was being fought far from reaching any military and political solution. Other comedies by Cañizares analyzed are La Poncella de Orleans, composed in cooperation with Antonio de Zamora and explicitly pro-French: it was composed in 1706 as well, and it was represented for the first time in Madrid in 1707, in order to celebrate the pregnancy of Maria Luisa of Savoy, Philip V's first wife. Finally, La banda de Castilla, y duelo contra sí mismo, is also considered: a manuscript witness of it, dating back to 1727, is kept in the BNE (Ms. 16.594). In the present essay, the comedies by Cañizares quoted above are studied in order to examine both their peculiar treatment of the past facing the playwright's present and the author's mindset swaying between the Baroque and the Enlightenment.

Keywords. Cañizares; Age between two centuries; History plays; Monarchy; Past; Present; Fiction; History.

José de Cañizares nació en Madrid en 1676, y falleció en su ciudad natal en 1750. Sus obras teatrales se empezaron a imprimir y a estrenar en 1696. Entró en Palacio en 1700, en 1702 se le nombró fiscal de comedias (encargo que ocuparía hasta su muerte), y en 1715 ya estaba trabajando al servicio del duque de Osuna, Francisco María de Paula Téllez Girón y Benavides, para pasar después a colaborar con el sucesor de este, José Téllez Girón y Benavides, alternando su actividad de bibliotecario con la de comisario de las fiestas reales ${ }^{1}$. Al vacilar entre la sensibi- 
lidad barroca por un lado, y la de los «novatores» de inicios del XVIII por otro², este comediógrafo fronterizo, más proclive a la imitatio que a la inventio, fue un hábil refundidor de la gran producción dramática áurea y cultivó los géneros más representados en los escenarios españoles desde mediados del XVII: es decir, comedias caballerescas, mitológicas, heroicas, históricas, hagiográficas, palatinas, de magia y de figurón. Sin lugar a dudas, en el panorama teatral de entresiglos, Cañizares, con su coetáneo y amigo Antonio de Zamora (1665-1727), formó un dúo célebre de ingenios cortesanos ${ }^{3}$ : ambos fueron admirados, aplaudidos e imitados en su época - según afirmaba Paul Merimée en un estudio pionero de 19834-, pero en la actualidad yacen casi olvidados por la crítica y el mundo de la farándula.

La naturaleza palaciega del teatro de Cañizares - por otra parte, palmaria por el abundante caudal de zarzuelas y fiestas que compuso, con un fastuoso aparato escenográfico y musical- se manifiesta en el género al que me dedico en este trabajo: el drama histórico. En efecto, bajo el lema ciceroniano historia magistra vitae, tanto en la comedia áurea ${ }^{5}$ como en la producción de este autor/epígono, los sucesos del pasado, mezclados con la ficción y la invención, siempre remiten al presente, con la finalidad de comprenderlo, cuestionarlo y presentarlo mejor. Al mismo tiempo, además, a través de la historia, Cañizares ejerce el didacticismo que más adelante caracterizaría las letras ilustradas ${ }^{6}$.

Ahora bien, a partir del año 1700 en la historia española ingresa el duque de Anjou, fundador de la dinastía de los Borbones, con el nombre de Felipe V. De ahí que Cañizares, ya protagonista de la cultura en la corte de Carlos II, esgrima todas sus armas humanas y literarias para congraciar al nuevo soberano francés, a las dos reinas italianas -María Luisa de Saboya (esposa de Felipe desde 1701 hasta la muerte de ella, en 1714), e Isabel de Farnesio (con quien Felipe se casa en 1714)-, y al entorno político y cortesano que los rodearon. En 1711 Cañizares participa con toda probabilidad en la Guerra de Sucesión (1702-1713), con el cargo de «capitánteniente de Caballos Corazas», pero en 1715 abandona la milicia ${ }^{7}$, para regresar a la labor de dramaturgo, en su papel de creador, de fiscal de comedias y de comisario de los festejos reales, como he dicho ${ }^{8}$. Más adelante, «con fecha de 25 de abril de 1736 fue nombrado Compositor de Letras Sagradas de la Real Capilla»9.

Entrando en el tema que me ocupa más directamente aquí, creo que es oportuno ante todo citar el «Prólogo» de la primera edición de las Comedias de Antonio de Zamora (1722) ${ }^{10}$, donde el dramaturgo, refiriéndose a su poética, incide en la

2. Ver Pérez Magallón, 2002

3. Los dos dramaturgos escribieron algunas obras en colaboración, como veremos, y hay constancia de que hayan asistido mutuamente a la puesta en escena de sus comedias

4. Ver Merimée, 1983.

5. Ver Matas Caballero, 2015

6. Ver Bègue y Mata Induráin (eds.), 2018.

7. Ver Leal Bonmatí, 2011, p. 24.

8. Ver Leal Bonmatí, 2008, p. 267.

9. Ver Herrera Navarro, 1992, p. 76.

10. Ver Zamora, Comedias nuevas... 
voluntad de «vestir al uso del siglo la historia». La misma intención contradistingue al teatro histórico de Cañizares. De hecho, en las comedias que pertenecen a este género, cuajadas de anacronismos y sincronismos, Cañizares (como Zamora) considera eventos que guardan relación con su propio tiempo y con los avatares de la política y de la corte borbónica a la cual quiere y debe rendir homenaje.

A este grupo de obras ${ }^{11}$ pertenece La poncella de Orleans ${ }^{12}$, muy probablemente escrita a cuatro manos con Zamora ${ }^{13}$, y explícitamente anti-inglesa y francófila. Se redactó en $1706^{14}$, en plena Guerra de Sucesión (aún lejos de su solución militar y política), y se estrenó en Madrid el 5 de mayo de 1707 por la compañía de Blas Polope $^{15}$, con el dúplice propósito de celebrar el primer embarazo de María Luisa de Saboya y de ensalzar a Felipe II de Borbón-Orléans (1674-1723), duque de Orléans y tío de Felipe $v$, quien a principios de 1707 obtuvo el mando de los ejércitos borbónicos de la mano de Luis XIV de Francia, cosechando varias victorias en Italia y, sobre todo, en la zona austriacista de Valencia, Cataluña y Aragón, hasta 170916, cuando el duque «fue llamado a París» por Luis XIV por sus peligrosas pretensiones a la corona española17. En las dramatis personae aparecen figuras reales y ficticias, como suele ocurrir en las piezas históricas. Entre las primeras destacan Carlos VII Valois, rey de Francia entre 1422 y 1461; Enrique V de Inglaterra, que, sin embargo, en la realidad reinó hasta 142218; Juana de Arco (1412-1431) -la legendaria pastora-guerrera que llevó a cabo la reconquista de importantes ciudades francesas a favor de Carlos VII y en contra de los ingleses, como Orléans (1429), antes de morir en Rouen, en 143119-; el duque de Borgoña Felipe III «el Bueno» (1419-1467), enemigo de Carlos VII y aliado de los ingleses hasta 1435; el duque de Alenquer, contrafigura del verdadero duque de Alençon, quien apoyó a Juana de Arco en la

11. Además de las comedias históricas de Cañizares que se consideran en este artículo, hay que mencionar por lo menos Carlos V sobre Túnez (que se estrenó el 26 de enero de 1711 en el Teatro del Príncipe de Madrid; ver Andioc y Coulon, 2008, vol. II, p. 656), El pleito de Hernán Cortés con Pánfilo de Narváez (estrenada en el Teatro de la Cruz en Madrid, el 15 de febrero de 1716; ver Andioc y Coulon, 2008, vol. II, p. 824), y El príncipe don Carlos (cuyo estreno se dio el 28 de septiembre de 1708 en el Teatro de la Cruz; ver Andioc y Coulon, 2008, vol. II, p. 833).

12. Ver Cattaneo, 1988.

13. Ver Herrera Navarro, 1992, pp. 81 y 489; Martín Martínez, 2010, vol. II, p. 678. En la BNE se conserva un testimonio manuscrito, con letra del siglo XVIII, atribuido a Antonio de Zamora y a José de Cañizares (Ms. 17309, 55 fols.: «Comedia nueva de d. Antonio de Zamora y d. José de Cañizares», fol. 2r).

14. Ver Urzáiz Tortajada, 2002, vol. II, p. 731.

15. Para la datación de esta comedia, ver la «Cronología de obras completas de Antonio de Zamora (Dramáticas y líricas)» que Jordi Bermejo Gregorio ha preparado como primer Anejo del segundo volumen de su tesis doctoral (Bermejo Gregorio, 2015, vol. II, p. 1064). Sobre la redacción de La poncella de Orleans, Bermejo Gregorio incluye la «Posible participación de José Cañizares».

16. Ver Albareda Salvadó, 2010, pp. 223 y ss.

17. Ver Albareda Salvadó, 2010, p. 280.

18. El monarca inglés, aliado de los borgoñones, que luchó contra Carlos VII durante las últimas fases de la Guerra de los Cien Años, para la supremacía en Francia, fue Enrique VI Lancaster, único hijo de Enrique $\checkmark$ y Catalina de Valois, quien gobernó desde la muerte de su padre (1422) hasta 1461.

19. Ver Bendriss, 2016. 
defensa de Orléans; el capitán inglés Talbot ${ }^{20}$. En cambio, entre los personajes de menor realce, algunos resultan indefinidos o inverosímiles, como el condestable de Francia ${ }^{21}$ y el Delfín de Francia, Luis ${ }^{22}$, mientras que otros son fruto de invención, como Madama Inés, amante inglesa de Carlos VII, y el gracioso Patín, cobarde y ridículo criado de la Poncella, detrás del cual podría encubrirse el escudero de Juana de Arco, Jean d'Aulon. Otro hito argumental de la comedia histórica, presente en La poncella de Orleans, es la conexión de la guerra con el amor: en la intriga secundaria, de tema amoroso, repercute la perspectiva desde la cual se interpreta el enfrentamiento bélico.

Las posibles fuentes historiográficas del texto dramático, que delinean la recepción «no [...] demasiado abundante» de la epopeya de Juana de Arco en la literatura española de los siglos $\mathrm{XV}$ y $\times \mathrm{VV} \mathrm{I}^{23}$, son el Libro de las bienandanzas e fortunas (1471-1476) de Lope García de Salazar, la Historia de Inglaterra Ilamada fruto de los tiempos de Rodrigo de Cuero (1509), el capítulo XLVI de la Crónica de Don Álvaro de Luna atribuida a Gonzalo Chacón (1517), la anónima Miscelánea históricogeográfica, escrita «con posterioridad a $1519{ }^{24}$, y, sobre todo, La poncella de Francia, una narración caballeresca en prosa, compuesta entre 1474 y 1491 e impresa a principios del siglo XVI, la única obra «dedicada por completo a la figura de la Doncella» en territorio hispánico 25 .

Al colocar la acción en los años 1429-1431, durante la Guerra de los Cien Años (1337-1453), la disputa dinástica franco-inglesa más larga y encarnizada del Medievo europeo, que «modificó de modo duradero el equilibrio interno de Europa» ${ }^{26}$ y marcó el pasaje a una nueva edad ${ }^{27}$, dos autores finiseculares como Cañizares y Zamora aluden a la Guerra de Sucesión Española, teatro de una fuerte contienda genealógica entre todas las grandes potencias de la época (Francia y España en contra de Inglaterra, del Sacro Imperio Romano y de las Provincias Unidas holandesas), cuya trascendencia fue fundamental para establecer el nuevo status quo militar y político de la Europa dieciochesca, especialmente en una España que daba la espalda a la decadencia barroca de los últimos Austrias y se abría al reformismo ilustrado de los Borbones. Sin lugar a dudas, la figura de Juana de Arco -enérgica, valiente y piadosa- reenvía al duque de Orléans en el momento de su máximo auge

20. Sir John Talbot, comandante de las tropas de Enrique VI, fue hecho prisionero en la batalla de Patay, que supuso una victoria aplastante de los franceses sobre los ingleses, el 18 de junio de 1429 (ver Nicolle, 2011, pp. 78-88).

21. En la época de Carlos VII, el Condestable de Francia era Arturo de Richemont, que «cayó en desgracia a finales de 1427 y huyó a Bretaña» (ver Nicolle, 2011, p. 9).

22. Mientras no se le coronó rey de Francia en la catedral de Reims, el 17 de julio de 1429, Carlos VII siguió siendo el Delfín. Su primer hijo se llamaba Luis, nació en 1423 y sería rey de Francia con el nombre de Luis XI «el Prudente» desde 1461 hasta 1483. Con todo, en la comedia de Zamora y Cañizares, el Delfín Luis se presenta como un valeroso combatiente, cuando en 1429 solo tendría seis años.

23. Ver Campo e Infantes, 2006, p. 15.

24. Ver Campo e Infantes, 2006, p. 19.

25. Ver Campo e Infantes, 2006, p. 16.

26. Ver Contamine, 2014, p. 136.

27. Ver también Perroy, 1982.

HIPOGRIFO, 8.2, 2020 (pp. 303-319) 
militar, cuando, por ejemplo, el 25 de abril de 1707 contribuyó con sus soldados al éxito en la batalla de Almansa, decisivo para los borbónicos, inaugurando una serie de victorias en el frente catalán (Lleida, 14 de noviembre de 1707, y Tortosa, 9 de julio de 1708 ${ }^{28}$. No es ninguna casualidad, por lo tanto, que la protagonista de La poncella de Orleans, obedeciendo a la llamada divina de «una sombra» ${ }^{29}$, sea alabada por Carlos VII, el Condestable de Francia, el Delfín Luis y todo el ejército francés por haber derrotado a los ingleses levantando el sitio de Orléans (como realmente sucedió, el 8 de mayo de 1429).

No obstante, mientras que la primera jornada reproduce fielmente los sucesos históricos, en el segundo acto se introducen hechos y motivos imaginarios, empezando por los amores entre el rey francés y la dama inglesa Inés, que, envidiosa de la estima real cosechada por la intrépida Juana de Arco, traiciona al monarca y pasa al bando rival. Bien es cierto, además, que en el verano de 1429 -como se alude genéricamente en las jornadas segunda y tercera de la comedia-, la Doncella y el ejército francés recobraron algunos castillos del Loira y vencieron a los ingleses en la importante batalla de Patay (18 de junio de 1429), avanzando hacia París, pero finalmente abandonando el propósito de retomar la capital por orden del temeroso Carlos VII (13 de septiembre de 1429) ${ }^{30}$. De todas formas, en el tercer acto, aparecen anacronismos e incorrecciones históricas relacionados con los últimos dos años de vida de Juana de Arco, traiciones cometidas con el probable propósito de defender y justificar la conducta del monarca francés.

Por consiguiente, la acción dramática respeta la historia cuando el duque de Borgoña captura a la Poncella -para luego venderla a los ingleses-durante el asedio de Compiègne, funesto para los franceses (24 de mayo de 1430), pero se aleja de la realidad referencial cuando el gracioso Patín alcanza el campo francés y avisa al rey de que Juana está encarcelada y los enemigos están preparando la hoguera donde la quemarán. Carlos VII y el duque de Alaquer se precipitan al cadalso y Juana de Arco fallece en brazos del rey, quien guía a sus soldados al ataque contra los ingleses para vengar la muerte de la joven. El desenlace, patético y heroico, elimina toda referencia al largo y humillante juicio-farsa al que Juana de Arco tuvo que someterse en Rouen, antes de arder con la acusación de herejía y hechicería, el 30 de mayo de $1431^{31}$. Sobre todo, por evidentes razones ideológicas, la comedia silencia y trastoca totalmente la actitud pasiva e irresoluta que Carlos VII tomó con respecto al prendimiento, a la condena y a la ejecución de la Poncella, porque en realidad el soberano nada hizo para exigir su liberación ni para salvarla: «se puso a negociar con el duque [de Borgoña] su rescate, pero rápidamente se retiró de la puja alegando que pedía demasiado»32. Es innegable, pues, que la figura de

28. Ver Albareda Salvadó, 2010, pp. 275 y ss.

29. He utilizado el texto de la comedia publicado en la segunda edición de las Comedias de Zamora

(1744), vol. I, fols. 195-242.

30. Ver Buraya, 2005, pp. 64-71.

31. Ver Buraya, 2005, pp. 75-152.

32. Ver Buraya, 2005, p. 76 
Carlos VII refleja a Felipe V, un rey frágil, no aficionado al poder y totalmente dependiente de la voluntad de sus dos autoritarias esposas ${ }^{33}$.

A una crisis política y sucesoria paralela a la que desencadenó la Guerra de Sucesión tras la muerte de Carlos II, se refiere otra pieza histórica de Cañizares muy cercana cronológicamente a La poncella de Orleans. Se trata de El pastelero de Madrigal, rey don Sebastián fingido ${ }^{34}$, que se compuso en 1706 y se estrenó en el Teatro del Príncipe de Madrid el 5 de diciembre de 170835. La intriga se sitúa en la época sucesiva al reinado de don Sebastián de Portugal (1554-1578) y a su muerte en 1578, durante la desastrosa batalla de Alcazarquivir, en la que los bereberes marroquíes derrotaron las tropas lusas ${ }^{36}$. Como explica el único editor moderno de la comedia, Rafael Lozano Miralles, «la desaparición [del joven monarca] sin herederos, [...] sume al trono portugués en graves dificultades. Se abre un período de luchas dinásticas que se concluyen en 1581 con la victoria y proclamación de Felipe II como rey y la consiguiente anexión de Portugal al imperio español», hasta la independencia portuguesa en 1640 y el «nombramiento del duque de Braganza como nuevo rey» ${ }^{37}$.

Tras el misterioso fallecimiento de don Sebastián en África y el surgir del mito del sebastianismo, según el cual el malogrado monarca portugués algún día volvería a reinar en su país, varios impostores intentaron hacerse pasar por él38, como, por ejemplo, en 1594, Gabriel de Espinosa, un pastelero del pueblo abulense de Madrigal de las Altas Torres. Alrededor de su figura y trayectoria gira la acción de la obra de Cañizares, quien enriquece con elementos amorosos y de capa y espada el enredo de abolengo histórico-político, centrado en un intento de apropiación del trono de Felipe II por su sobrina María Ana de Austria, el fraile agustino Miguel dos Santos y el propio Espinosa, ahorcado en 1595 después de haber sido juzgado ${ }^{39}$. A las fases del proceso penal se refiere el tercer acto de la comedia, que se basa en la breve Historia de Gabriel de Espinosa, pastelero en Madrigal, que fingió ser el rey

33. Ver Kamen, 2010, pp. 118 y ss.; Vázquez Gestal, 2013; también ver Erlanger, 2003.

34. Hasta la monografía de Paul Merimée sobre Zamora y Cañizares (1983), la comedia se atribuyó a Jerónimo de Cuéllar. En su edición crítica de El pastelero..., Lozano Miralles (pp. 19-23) escoge como testimonio base el manuscrito con letra del siglo XVIII, conservado en la BNE e incluido en la colección autógrafa Flor de comedias nuevas muy selectas que no están impresas. Su autor don Joseph de Cañizares (Ms. 22.230): nuestra obra es la tercera (fols. 150r-217v).

35. La pieza se escenificó a menudo en los teatros madrileños durante el siglo XVIII (ver Andioc y Coulon, 2008, vol. II, p. 816). En lo que atañe a los testimonios impresos, el primero en orden temporal del que disponemos es una suelta publicada en Madrid (Antonio Sanz) en 1746, que sin embargo se atribuye a «un ingenio de esta corte», no directamente a Cañizares.

36. Ver Queiroz Veloso, 1943

37. Ver Lozano Miralles, en su edición de El pastelero de Madrigal, p. 5.

38. Sobre el movimiento místico-secular del sebastianismo, he consultado a Casamar Pérez, 1995, y a Villacorta Baños-García, 2001.

39. El expediente completo de los actos del proceso contra Miguel dos Santos y Gabriel de Espinosa se halla en el Archivo General de Simancas (Sección de Estado, legajos 172-173). Al respecto, ver Lozano Miralles, en su edición de El pastelero de Madrigal, p. 8. 
don Sebastián de Portugal. Y asimismo la de fray Miguel de los Santos, en el año de $7595^{40}$.

Por otra parte, no cabe duda de que el tema de la conspiración urdida en contra de Felipe II se asocia a la voluntad de Cañizares de adherirse al absolutismo monárquico del joven Felipe $\mathrm{V}$, condenando toda tentativa de conjuración y rebelión en la turbulenta corte de este, agitada por los contrastes entre la insumisa nobleza española y la nueva elite gobernante francesa. Además, aquellos mismos años estuvieron plagados de deserciones y sublevaciones anti-felipistas, sobre todo en la región valenciana y en Cataluña, donde el archiduque Carlos III, hijo del emperador Leopoldo I de Habsburgo y pretendiente a la corona española, gobernó desde 1705 hasta 1711, cuando como nuevo emperador del Sacro Imperio Romano Germánico, «con el título de Carlos VI», salió «de Barcelona para siempre» ${ }^{41}$.

Por consiguiente, en El pastelero de Madrigal Gabriel de Espinosa se presenta bajo una luz negativa como el fingidor y el usurpador por excelencia, no solo de la corona portuguesa - según él mismo cuenta en un amplio romance de la primera jornada, jugando el papel de don Sebastián (vv. 297-488, pp. 40-46)-, sino también del corazón de dos mujeres: Clara de los Reyes, a quien ha abandonado tras tener una hija con ella, y su dueña doña Leonor de Vasconcelos, a quien ha enamorado con el nombre falso de Juan de Silva. Asimismo, Gabriel está rodeado por una serie de personajes inventados, ridículos y de ínfimo nivel social, que subrayan su bajeza moral: Catuja, su asistente de cocina; su criado Moscón, los graciosos Rodelos y Maravete. Sin embargo, el protagonista expresa su sentimiento de culpabilidad y teme su castigo futuro, cuando se dirige a Miguel de los Santos con estas palabras:

GABRIEL ¿Parécete a ti, Miguel,

(hablémonos sin disfraces)

que esta exquisita maraña

puede pasar adelante

sin que siendo descubiertos

nuestras dos vidas lo paguen? (II, vv. 1065-1070, pp. 74-75).

Efectivamente, aunque amenizada bien por los lances de los siervos bufos y de la criada Inés, bien por la trama amorosa -en la que Leonor oscila entre su pasión por Gabriel y el cortejo de don Fadrique de Castilla y de don Rodrigo de Santillana-, la acción discurre hacia su obligado desenlace serio. En la segunda jornada (vv. 1966-1971) se detiene a Espinosa por mandato de Rodrigo de Santillana, alter ego ficticio del verdadero Rodrigo de Santillán, alcalde del crimen de la Chancillería vallisoletana que arrestó a Espinosa en 1594 y lo condenó a muerte tras un juicio por lesa majestad. Y en el tercer acto siguen la confesión de Miguel de los Santos (III, vv. 2726-2817) y el ajusticiamiento de Gabriel, que se evoca, sin mostrarse explícitamente en el escenario, siendo anticipado por la compungida súplica final del pastelero: 


$\begin{array}{ll}\text { GABRIEL } & \text { La muerte os pido, no anhelo } \\ & \text { piedad, pues sé que me espera } \\ & \text { el gran Dios, cuya virtud } \\ & \text { ningún pecador desprecia; } \\ & \text { al rey le pido perdón, } \\ & \text { y a todos, pecho en tierra. } \\ & \text { iLlevadme a morir! (III, Vv. 2890-2896, p. 158). }\end{array}$

Por lo tanto, como en toda comedia áurea que se respete, y más aún en esta pieza, impregnada de ideología pro-monárquica y pre-ilustrada, los equilibrios se re-establecen en la conclusión, donde don Rodrigo impone la justa pena a los culpables y celebra las nupcias de Leonor con Fadrique, que dan pie a las bodas serviles de Moscón con Catuja y de Rodelos con Inés:

RODRIGO
Poco tuviera
que temer de quien se sabe
$[\ldots]$
que era hombre de bajas prendas,
que hurdió tan extraño embuste.
De Miguel queda suspensa
la causa, hasta otra ocasión,
en que su muerte les sea
escarmiento a más de dos;
y ya se dio penitencia
a la señora doña Ana
y sus criadas, que llevan
con suma resignación;
Clara con su hija queda
en un convento, después
que casó Gabriel con ella (III, vv. 2987-3003, p. 164).

Al género de privanza se adscribe más bien, en cambio, la comedia quizá más acertada de Cañizares en el pequeño corpus seleccionado para esta ocasión: es El picarillo en España, señor de la Gran Canaria, y está ambientada en el sombrío tiempo de Juan II Trastámara (1406-1454) y de su poderoso valido Álvaro de Luna, Condestable de Castilla de 1423 a 145342. La obra se estrenó en el teatro madrileño de la Cruz el 13 de mayo de $1716^{43}$, ya finalizada la guerra, y permaneció con fre-

42. Sobre esta pieza en especial, con relación a las letras medievales y a las tablas del XVII, ver Londero, $2017,2018 a$ y $2018 b$

43. En la BNE se hallan un testimonio manuscrito de 1725, el Ms. 15539 (57 fols.), atribuido a Cañizares, y dos sueltas: una de 1747 (Madrid, Antonio Sanz) y otra de 1763 (Valencia, Viuda de José de Orga), ambas a nombre del autor (ver Herrera Navarro, 1992, p. 81; Urzáiz Tortajada, 2002, vol. I, p. 223). La Barrera (1860, pp. 68-69) manifiesta su incertidumbre sobre la autoría: «Ofrécense dudas acerca de la legítima pertenencia a don José de Cañizares de dos de las mejores piezas que corren con su nombre. Don Vicente Suárez de Deza y Ávila, en el año de 1663 (don José de Cañizares nació el de 1676), citó una comedia titulada: El Picarito en España; entre los títulos de ellas, que intercaló en la suya burlesca: Amor, ingenio y mujer, inserta por él en su Primera parte de Los donaires de Tersícore. - Madrid, 1663. La 
cuencia en cartelera desde 1717 hasta $1807^{44}$. Con vistas a conseguir sus objetivos en la corte de Felipe V, Cañizares reelabora libremente sus modelos historiográficos, poéticos y teatrales. Un rápido espigueo en la vertiente medieval no puede descartar la Crónica de Juan II de Castilla de Álvar García de Santamaría (1406-1434), refundida en 1517 por Lorenzo Galíndez de Carvajal, la Crónica de don Álvaro de Luna, atribuida a Gonzalo Chacón (1517), la Crónica del Halconero (1420-1441) de Pedro Carrillo de Huete (c. 1380-1448), las Generaciones y semblanzas de Fernán Pérez de Guzmán (1512), el Romancero de don Álvaro de Luna, el Laberinto de Fortuna de Juan de Mena (1444) y el Cancionero de Baena (1426-1435). Por otra parte, entre los hipotextos dramáticos áureos destacan una comedia de privanza de Damián Salucio del Poyo (La privanza y caída de don Álvaro de Luna, 1601), la bilogía de Antonio Mira de Amescua (La próspera fortuna de don Álvaro de Luna, 1618-1621, y La adversa fortuna de don Álvaro de Luna, 1621-1624), y El privado perseguido de Luis Vélez de Guevara, compuesta en los primeros años veinte del XVII y muy escenificada a lo largo del siglo XVIII ${ }^{45}$.

Al escoger la turbia época de Juan II, Cañizares expresa su elogio de Felipe V de forma encubierta, pero al mismo tiempo critica el bamboleo del rey entre los bandos nobles que se enfrentaron en su corte -la aristocracia española, la minoría gobernante francesa y los favoritos italianos que llegaron a España en el séquito de Isabel de Farnesio a partir de 171446. De hecho, tal como sus modelos áureos, el dramaturgo madrileño se sirve de personajes y sucesos del tiempo del penúltimo Trastámara con la finalidad de poner en tela de juicio la edad de Felipe v. Además, respetando los cimientos conceptuales y el andamiaje estructural de la comedia de privanza, el autor «ofrece una pintura fiel de las interioridades de la corte» ${ }^{47}$, construida como un «espacio de poder» ${ }^{48}$.

Yuxtaponiendo el pasado y el presente, Cañizares mezcla las res factae con las res fictae, de manera que «lo histórico está al servicio de la ficción» 49 . En consecuencia, los episodios y los protagonistas reales se eliminan, se retocan y se intercambian, para demostrar ideas, preceptos y normas de comportamiento siempre válidos en el mundillo de la corte, mudable y violento como el campo de batalla. Estos son los dos espacios donde se mueven los personajes y se desenvuelve el enredo, dividido a su vez en dos tramas -la bélico-política y la amorosa-, como ocurre en la comedia barroca, y en dos niveles sociales: el alto, poblado por reyes, nobles, galanes y damas, y el bajo, ocupado por soldados, graciosos y criadas.

atribuida a Cañizares (don José) se titula: El Picarillo en España». Al contrario, Herrera Navarro y Urzáiz Tortajada la atribuyen con seguridad a Cañizares.

44. Ver Andioc y Coulon, 2008, vol. II, pp. 822-823

45. Ver Crivellari, 2012, pp. 53-56.

46. Ver Kamen, 2010, p. 140

47. Ver Ochoa, 1838, p. 398.

48. Ver Ferrer Valls, 2004, p. 168.

49. Ver Rull, 1979, p. 860. 
Como también se acostumbra en el teatro histórico áureo, según hemos visto, los personajes cómicos y socialmente inferiores son ficticios: el gracioso Bambute y su enamorada Inés, las criadas Nise y Cloris. Al contrario, la mayoría de las figuras de elevada alcurnia reflejan a sus modelos auténticos, aunque otras veces Cañizares reúne a varias personas en una sola. Pertenecen a la realidad Juan II, el Infante Enrique, Álvaro de Luna, Isabel de Portugal, [Alonso] Yáñez Fajardo - partidario del monarca desde 1422 y Adelantado mayor de Murcia desde 1423-, además de Pedro Manrique, padre de Rodrigo y abuelo del gran poeta Jorge. En cambio, dos personajes de segunda fila, Gómez de Herrera y el Cardenal Pedro Carrillo, remiten a un conjunto de figuras históricas diferentes y solapadas. Pedro Carrillo de Toledo, Aposentador mayor de Juan II, nunca fue cardenal, mientras que Alonso Carrillo de Acuña fue Arzobispo de Toledo desde 1445. Para crear a Gómez Herrera, es posible que Cañizares pensara en Ruy Gómez de Herrera, quien en 1442 era Escribano de cámara del rey, o bien en Fernando Gómez de Herrera, Recaudador mayor en el Reino de Murcia durante la monarquía de Juan II.

En cuanto a la pareja noble principal, Leonor de Urrea y Federico de Bracamonte, están en vilo entre la historia y la fantasía. La familia Urrea apoyó al Infante Enrique contra Juan II y el Condestable, pero no consta que haya vivido en la corte ninguna Leonor de Urrea, que en la ficción dramática es la dama de compañía de la reina Isabel. Por lo que concierne al galán Federico, este es el hijo imaginario de Rubín de Bracamonte o Robert de Braquemont, un almirante que realmente obtuvo de la reina Catalina de Lancaster, madre de Juan II, el derecho de conquistar Canarias para un primo suyo, el barón normando Jean IV de Béthencourt, según se narra en el capítulo IV (1417) de la Crónica de Juan I/50.

En lo que atañe a los sucesos históricos reconstruidos, en general Cañizares respeta la actitud de los comediógrafos áureos, quienes siembran anacronismos y sincronismos en el texto. Este empieza con una batalla encarnizada donde combaten los dos ejércitos enemigos, según ilustra la primera acotación: «Tocan cajas y clarines, y salen dándose batalla, de la una parte el Rey don Juan, don Álvaro de Luna, Federico mal vestido, Bambute roto y tiznado, y don Yáñez Fajardo, y de la otra el Infante don Enrique, don Gómez de Herrera, don Pedro Manrique y soldados»51. Se trata de la batalla de Olmedo (1445): «Ya está la villa / de Olmedo desocupada; / y fugitivo el Infante, / con pocos que le acompañan / marchando va [...]» (I, vv. 194198, p. 3). No obstante, en ella están presentes Yáñez Fajardo, que había muerto en 1444, y la reina Isabel, que se casó con Juan II dos años después, el 22 de agosto de $1447^{52}$. Es más: en El picarillo..., la victoria del Trastámara se debe sobre todo a

50. Ver Mata Carriazo, 1946. Sobre la primera fase de la conquista del archipiélago (1402-1477), ver Castellano Gil y Macías Martín, 1993; Jiménez del Castillo, 2004. En el teatro aurisecular, la conquista normanda, y después castellana, del archipiélago canario a partir de principios del siglo Xv, ya había sido el tema principal de dos comedias de Lope: Los guanches de Tenerife y conquista de Canaria, redactada entre 1604 y 1606, y publicada en la Parte décima (1618) de sus comedias, y San Diego de Alcalá, escrita probablemente en 1613 (ver Brito Díaz, 1998; Castells Molina, 1998).

51. Uso como base textual la suelta impresa en Valencia, por la Viuda de José de Orga, 1763 (pp. 1-32), modernizando la grafía, la acentuación y la puntuación.

52. Ver Calderón Ortega, 1998, p. 76. 
la porfía de Federico, caballero forastero y misterioso, cuyas proezas militares el rey premia acogiéndole en su corte.

En el tercer acto los desajustes temporales aumentan: la acción se desarrolla en parte durante el cerco del castillo de La Puebla de Montalbán, que el Infante Enrique puso en 1420 ( 25 años antes de Olmedo), mientras Juan II y Álvaro de Luna estaban refugiados allí. La comedia finaliza con dos acontecimientos, el primero histórico y el segundo fruto de invención: por un lado, la fuga verdadera que Enrique emprendió desde la fortaleza de Montalbán tras levantar el asedio al haber perdido muchos apoyos entre sus aliados, y por otro, la anagnórisis de Federico ante Juan II, quien perdona al padre del joven, supuestamente culpable de haber traicionado la corona castellana cediendo Canarias a Portugal, y generando un conflicto entre los dos reinos. En la realidad, Robert de Braquemont no cumplió este acto, y Castilla ratificaría su soberanía sobre el archipiélago en 1479, firmando el Tratado de Alcaçovas con Portugal.

Otro elemento típico de El picarillo en España es el hecho de que Cañizares vincula la trayectoria vital y política de Álvaro de Luna a la inconstancia de los poderosos y a la fortuna voltaria, un tema privativo del género de privanza. De ahí que en un largo diálogo con Federico (II, vv. 926-1060), el valido se niegue a alejarse de la corte y del rey porque teme su reacción imprevisible: «Porque, si del rey me aparto, / en su genio, que es mudable, / ver muchos males aguardo» (II, vv. 985-987, p. 12). De esta forma, Álvaro de Luna, como todos los privados de los dramas áureos, expresa ese terror «ante cualquier cambio de actitud del monarca» que cuestionaba su misma «identidad personal» y social ${ }^{53}$. Pocos versos antes, además, Federico dibuja la fortuna inestable en términos pictóricos, siguiendo la iconografía que los dramaturgos auriseculares hallaban en la emblemática y la mitografía, de las que solían echar mano para ampliar su repertorio metafórico y figurativo. La fortuna ciega se compara con una pintora que diseña y borra el hado de los hombres a su antojo:

FEDERICO Pues, señor, como yo estoy

a pícaro destinado,

pintar veo la fortuna,

porque estoy fuera del cuadro:

ella usa sombras y lejos,

luces y matices, dando

su imagen a los acasos;

pero es torpe como ciega,

y al tiempo solo estampando,

lo que imprime con la una,

lo borra con la otra mano.

[...].

En vos ya pintó la suerte

cuanto pudo [...]

[...].

No sé si fuera acertado

apartar el lienzo, antes 
que ella pudiera tocarlo

con la mano con que borra

(II, vv. 952-963, 968-969, 973-976, p. 12).

En este coloquio crucial, aligerado solo por unas breves y cómicas intervenciones de Bambute, salta a la vista la inmensa diferencia entre la ambición devoradora y la prepotencia del Condestable -en la cima de su poderío, pero envidiado y aborrecido - y la desenfadada postura de beatus ille que contradistingue a Federico, quien prefiere la pobreza y la errancia a una vida amarrada por la sospecha y la inquietud. El mensaje aleccionador para Felipe v y su entorno está al alcance.

Este breve recorrido por cuatro piezas históricas de Cañizares cargadas de motivos ideológicos y políticos concluye con la que considero la menos lograda de ellas, si bien no está exenta de interés por la tesis que aquí defiendo: me refiero a $L a$ banda de Castilla, y duelo contra sí mismo, puesta en escena por primera vez el 4 de mayo de 1709 en el Teatro del Príncipe de Madrid ${ }^{54}$. Aunque no se puede definir exactamente una comedia de privanza, esta obra de fondo histórico medieval -situada en el reinado de Alfonso XI de Castilla «el Justiciero» (1312-1350) y la pugna fronteriza contra los benimerines magrebíes y el rey moro de Granada- una vez más habla de un soberano que debe dominar no solo a sus adversarios externos (los moros, representados por el rey granadino Mahomad y el general africano Ozmín), sino sobre todo a una nobleza prepotente y hostil, simbolizada aquí por Álvar Núñez de Osorio y Garcilaso I de la Vega, personajes que remiten a homónimos validos de Alfonso XI, a la vez acérrimos rivales de otro peligroso privado del mismo rey, don Juan Manuel ${ }^{55}$.

No obstante, en La banda de Castilla, y duelo contra sí mismo, las vagas referencias a la Reconquista y a las luchas entre las diversas facciones aristocráticas en la corte de Alfonso XI se rebajan a un plano secundario ante la importancia que cobra el tema amoroso. Este se relaciona en especial con doña Leonor Nuño, virgo bellatrix crecida al amparo de la hermana de Mahomad, Zorayda, después de que su padre Juan ha sido perseguido y ejecutado por el rey Alfonso a raíz de unos desacuerdos políticos. Vestida de hombre y acompañada por la criada Inés, Leonor cruza la frontera entre Castilla y el reino granadino para recobrar el honor perdido de su defunto padre, y salva la vida del monarca castellano durante una batalla contra las huestes de Ozmín. De ahí que la belleza y el valor de Leonor hagan enamorar a Mahomad, al rey Alfonso y a su privado Garcilaso, quienes se contienden los favores de la dama hasta que en el final este último consigue desposarla, con la bendición del soberano.

54. Ver Andioc y Coulon, 2008, vol. II, p. 640. De esta comedia existe un testimonio manuscrito atribuido a José de Cañizares y fechado a 1727, que se conserva en la BNE (Ms. 16.594), donde también se encuentra una suelta recogida en un volumen facticio formado por 20 comedias e impreso en Madrid en 1747 (Antonio Sanz) (BNE, T/14821(7).

55. Ver Sánchez Arcilla, 2008. 
Si se transfiere la materia político-bélica de las cuatro comedias analizadas, rememorando la validez presente que siempre abrigaba el pasado no solo para los dramaturgos del XVII, sino también para sus tardíos continuadores (como Cañizares) y sus sucesores neoclásicos e ilustrados, no se tarda en detectar en los reyes literaturizados -Carlos VII Valois, Juan II Trastámara y Alfonso XI de Castilla- a contrafiguras de Felipe $\mathrm{V}$ : un monarca débil, aquejado por ataques depresivos, enamoradizo y a merced de la fuerza de carácter y la destreza política de sus dos esposas, cuando no de validos ambiciosos, como lo sería Giulio Alberoni, Primer Ministro de 1715 a 1719. Por ende, un literato cortesano y finisecular como Cañizares, balanceándose entre la cómoda sumisión al poder y la fe en la autonomía artística, critica a Felipe $v$ de forma velada e indirecta y entre líneas le aconseja que no confíe demasiado en sus altos consejeros y adopte una conducta independiente y firme. Asimismo, la reprobación de toda inquietud y rebeldía frente a la autoridad monárquica, con su implícita llamada al orden y a la mesura, que en particular se desprende de El pastelero de Madrigal y de El picarillo en España, bien se enlaza con la postura cultural y humana de un escritor de entresiglos como José de Cañizares, abocado a la racional armonía de los extremos y al didacticismo a los que aspiraría la llustración.

\section{Bibliografía}

Albareda Salvadó, Joaquim, La guerra de Sucesión de España (1700-1714), BarceIona, Crítica, 2010.

Andioc, René, y Coulon, Mireille, Cartelera teatral madrileña del siglo XVIII (17081808), Madrid, Fundación Universitaria Española, 2008, 2 vols.

Barrera y Leirado, Cayetano Alberto de la, Catálogo bibliográfico y biográfico del teatro antiguo español, desde sus orígenes hasta mediados del siglo XVIII, ed. facsímil, Madrid, Gredos, 1969 [1860].

Bègue, Alain, y Mata Induráin, Carlos (eds.), Hacia la Modernidad. La construcción de un nuevo orden teórico-literario entre Barroco y Neoclasicismo, Vigo, Academia del Hispanismo, 2018.

Bendriss, Ernest, Juana de Arco, la doncella de Dios, Madrid, Mandala Ediciones, 2016.

Bermejo Gregorio, Jordi, La dramaturgia poético-musical de Antonio de Zamora. Estudio de las fiestas reales barrocas en un autor de finales del siglo XVII y principios del XVIII, tesis doctoral, dir. Lola Josa, Barcelona, Universidad de Barcelona, 2015, 2 vols.

Brito Díaz, Carlos, «Canarias y América: el mundo aborigen en dos piezas teatrales de Lope de Vega», en América y el teatro español del Siglo de Oro. Actas del II Congreso Iberoamericano de Teatro, ed. Concepción Reverte Bernal y Mercedes de los Reyes Peña, Cádiz, Servicio de Publicaciones de la Universidad de Cádiz, 1998, pp. 409-421. 
Buraya, Luis Carlos, Juana de Arco. La doncella de hierro, Madrid, EDIMAT, 2005.

Calderón Ortega, José Manuel, Álvaro de Luna: riqueza y poder en la Castilla del siglo XV, Madrid, Dykinson, 1998.

Campo, Victoria, e Infantes, Víctor, «Introducción», en La Poncella de Francia. La historia castellana de Juana de Arco, ed. Victoria Campo y Víctor Infantes, Madrid / Frankfurt am Main, Iberoamericana / Vervuert, 2006, pp. 7-85.

Cañizares, José de, El pastelero de Madrigal, rey don Sebastián fingido, ed. Rafael Lozano Miralles, Parma, Zara, 1995.

Cañizares, José de, El picarillo en España, señor de la Gran Canaria, Madrid, Viuda de José de Orga, 1763.

Casamar Pérez, María Remedios, Las dos muertes del rey don Sebastián, Granada, V Books, 1995.

Castellano Gil, José María, y Macías Martín, Francisco J., Historia de Canarias, Santa Cruz de Tenerife, Centro de la Cultura Popular Canaria, 1993.

Castells Molina, Isabel, «"Suele Amor trocar con Marte las armas": la conquista erótica y militar del Nuevo Mundo en tres comedias de Lope de Vega», Anuario Lope de Vega, 4, 1998, pp. 87-96.

Cattaneo, Mariateresa, «En torno a La Poncella de Orleans de Antonio de Zamora», en Coloquio Internacional sobre el teatro español del siglo XVIII, ed. Mario di Pinto, Maurizio Fabbri y Rinaldo Froldi, Abano Terme, Piovan, 1988, pp. 133-140.

Contamine, Philippe, La guerra de los cien años, trad. esp. Miguel Martín, Madrid, Rialp, 2014 [1968].

Crivellari, Daniele, «Introduzione», en Luis Vélez de Guevara, El privado perseguido, ed. Daniele Crivellari, Lucca, II Molo, 2012, pp. 13-92.

Erlanger, Philippe, Felipe v, esclavo de sus mujeres, Barcelona, Ariel, 2003.

Ferrer Valls, Teresa, «El juego del poder: Lope de Vega y los dramas de la privanza», en Modelos de vida en la España del Siglo de Oro. I. El noble y el trabajador, coord. Ignacio Arellano y Marc Vitse, Madrid, Casa de Velázquez, 2004, pp. 159-186.

Herrera Navarro, Jerónimo, Catálogo de autores teatrales del siglo XVIII, Madrid, Fundación Universitaria Española, 1992.

Jiménez del Castillo, Arquímedes, Historia del Reyno de las Islas Canarias (13441525). Descubrimiento, conquista y colonización, La Laguna, Ayuntamiento de la Laguna (Concejalía de Cultura), 2004.

Kamen, Henry, Felipe v. El rey que reinó dos veces, Madrid, Temas de Hoy, 2010.

Leal Bonmatí, María del Rosario, «José de Cañizares (1676-1750): un panorama crítico, una reivindicación literaria», Revista de literatura, LXIX, 138, 2007, pp. 487-518. 
Leal Bonmatí, María del Rosario, «José de Cañizares (1676-1750): una revisión biográfica», Dieciocho, 31.2, 2008, pp. 241-276.

Leal Bonmatí, María del Rosario, «El autor y la época. José de Cañizares (16761750) y el teatro entre dos siglos (1680-1724)», en José de Cañizares, Acis y Galatea, ed. María del Rosario Leal Bonmatí, Madrid / Frankfurt am Main, Iberoamericana / Vervuert, 2011, pp. 19-25.

Londero, Renata, «Juan II y su corte en las tablas post-barrocas: El picarillo en España (1716) de José de Cañizares», Crítica hispánica, XXXIX, 2, 2017 (monográfico «Poesía y corte en tiempos del Cancionero de Baena: creación y recepción», dir. Antonio Chas Aguión), pp. 135-155.

Londero, Renata, «Historia y ficción al servicio del poder: El picarillo en España (1716) de José de Cañizares», en El teatro clásico español: ayer y hoy, ed. Luciana Gentilli y Renata Londero, Madrid, Visor, 2018a, pp. 141-155.

Londero, Renata, «La corte de Juan II en el teatro de los siglos XVII y XVIII, con vistas a un catálogo», en Escritura y reescrituras en el entorno literario del «Cancionero de Baena», ed. Antonio Chas Aguión, Berlín, Peter Lang, 2018b, pp. 165-182.

Lozano Miralles, Rafael, «Introducción», en José de Cañizares, El pastelero de Madrigal, rey don Sebastián fingido, ed. Rafael Lozano Miralles, Parma, Zara, 1995, pp. 5-24.

Martín Martínez, Rafael, «Antonio de Zamora», en Diccionario filológico de literatura española (siglo XVII), dir. Pablo Jauralde Pou, coord. Delia Gavela García y Pedro C. Rojo Alique, Madrid, Castalia, 2010, vol. II, pp. 674-685.

Mata Carriazo, Juan de, «El capítulo de Canarias en la Crónica de Juan Il», Revista de historia de la Facultad de Filosofía y Letras de la Universidad de la Laguna, 73, 1946, pp. 1-9.

Matas Caballero, Juan, «"La fuerza de las historias representada". Reflexiones sobre el drama histórico: Ios reyes de la historia de España en los teatros del Siglo de Oro», en Tiempo e historia en el teatro del Siglo de Oro, ed. Isabelle Rouane Soupault y Philippe Meunier, Aix en Provence, Presses Universitaires de Provence, 2015, pp. 58-101.

Merimée, Paul, L'art dramatique en Espagne dans la première moitié du XVIII' siècle, Toulouse, Université de Toulouse-Le Mirail, 1983.

Nicolle, David, La heroína de Orleans, trad. esp. José Gortázar Azaola, Madrid, SGEL, 2011 [2001].

Ochoa, Eugenio de, Tesoro del teatro español desde su origen (año de 1356) hasta nuestros días, vol. V, Teatro escogido desde el siglo XVII hasta nuestros días, París, Librería europea de Baudry, 1838.

Pérez Magallón, Jesús, Construyendo la modernidad: la cultura española en el tiempo de los novatores (1675-1725), Madrid, CISIC, 2002. 
Perroy, Édouard, La Guerra de los Cien Años, Madrid, Akal, 1982.

Queiroz Veloso, José María, Don Sebastián, 1554-1578, trad. esp. Ramón de Garcíasol, Madrid, Espasa Calpe, 1943.

Rull, Enrique, «El Picarillo en España, de José de Cañizares», en La picaresca. Orígenes, textos y estructuras, ed. Manuel Criado de Val, Madrid, Fundación Universitaria Española, 1979, pp. 849-861.

Sánchez Arcilla, José, Alfonso XI (1312-1350), Gijón, Trea, 2008 [1995].

Urzáiz Tortajada, Héctor, Catálogo de autores teatrales del siglo XVII, Madrid, Fundación Universitaria Española, 2002, 2 vols.

Vázquez Gestal, Pablo, Una nueva majestad. Felipe v, Isabel de Farnesio y la identidad de la monarquía (1700-1729), Sevilla / Madrid, Fundación de Municipios Pablo de Olavide / Marcial Pons Historia, 2013.

Villacorta Baños-García, Antonio, Don Sebastián, rey de Portugal, Barcelona, Ariel, 2001.

Zamora, Antonio de, Comedias nuevas, con los mismos sainetes con que se ejecutaron, así en el Coliseo del Sitio Real del Buen Retiro, como en el Salón de Palacio, y teatros de Madrid, Madrid, Diego Martínez Abad, 1722.

Zamora, Antonio de, Comedias de don Antonio de Zamora, Madrid, Joaquín Sánchez, 1744, 2 vols. 